\title{
Water absorption variability of recycled concrete aggregates
}

\section{Miquel Joseph}

Department of Civil Engineering, Technology Cluster Construction $@$ Kulab, Faculty of Engineering Technology, KU Leuven, Ostend, Belgium Luc Boehme

Department of Civil Engineering, Technology Cluster Construction @Kulab, Faculty of Engineering Technology, KU Leuven, Ostend, Belgium

\section{Zeger Sierens}

Department of Civil Engineering, Technology Cluster Construction

@Kulab, Faculty of Engineering Technology, KU Leuven, Ostend, Belgium Lucie Vandewalle

Department of Civil Engineering, Division of Building Materials, Faculty of Engineering Science, KU Leuven, Ostend, Belgium

The programme ValReCon 20 has demonstrated the possibility of replacing up to $100 \%$ of coarse virgin aggregates with coarse recycled concrete aggregates (CRCA) in concrete of strength class C25/30. Recycled concrete from building demolition is a heterogeneous material, resulting in a higher standard deviation of many properties of CRCA. One of the important properties of CRCA, needed to design concrete mixes, is water absorption, but the heterogeneous nature of CRCA makes it harder to predict the actual amount of water that will be absorbed by CRCA during the mixing process. This paper compares the effects of over- and underestimation of the water absorption of CRCA. Various properties were investigated and the results show large differences in the workability and density of fresh concrete, water absorption by submersion and capillarity of the hardened concrete, dynamic modus of elasticity and mechanical strength properties.

\author{
Notation \\ A constant \\ a total volume of air \\ $c$ absolute volume of cement \\ $D \quad$ maximum particle size $(\mathrm{mm})$ \\ $d \quad$ sieve width ( $\mathrm{mm}$ ) \\ $f_{\text {c,cub }} \quad$ compressive strength \\ $K$ cement constant \\ $w \quad$ total volume of water \\ $y \quad$ pass-through sieve $D \mathrm{~mm}(\%)$ \\ $\rho_{\mathrm{a}} \quad$ absolute density $\left(\mathrm{kg} / \mathrm{m}^{3}\right)$ \\ $\rho_{\text {rd }} \quad$ apparent dry density $\left(\mathrm{kg} / \mathrm{m}^{3}\right)$ \\ $\rho_{\text {ssd }} \quad$ saturated density $\left(\mathrm{kg} / \mathrm{m}^{3}\right)$ \\ $\sigma \quad$ standard deviation
}

\section{Introduction}

Most aggregates currently used in concrete are of natural origin, excavated from quarries or dredged from river and sea beds, leading to ecological pressure. Fortunately, however, building demolition produces recyclable debris. In 2012, more than $11 \mathrm{Mt}$ of rubble were processed as recycled aggregates. This was further divided into three main aggregate categories - recycled concrete, red brick and mixed (Ovam, 2014). The research presented here is limited to the use of coarse recycled concrete aggregates (CRCA). Currently, most recycled aggregates are used in lowgrade applications such as road foundations and lean concretes. Consumer distrust and the behaviour of recycled aggregates are the two main reasons why they are currently restricted to lowlevel use. However, research has shown that recycled debris can replace coarse natural aggregates in several concrete high-end applications (Boehme et al., 2012; Pavlů and Boehme, 2013).

One important difference between CRCA and natural aggregates is water absorption. The high water absorption of CRCA is linked to the presence of old mortar (de Juan and Gutierrez, 2009). Dry recycled aggregates behave like sponges in fresh concrete, thus impacting on the water/cement ratio $(\mathrm{w} / \mathrm{c})$ ratio. This ratio represents the water mass to cement mass ratio in a concrete mix, and is used as an indicator of durability and strength development.

When aggregates with high water absorption are used in concrete, the $\mathrm{w} / \mathrm{c}$ ratio may be replaced by the effective water/cement ratio $\left(\mathrm{w} / \mathrm{c}_{\mathrm{eff}}\right)$, which uses the total amount of water minus the amount of water absorbed by the aggregates. NBN B 15-001 accepts this use as a durability criterion for designing concrete (WTCB, 2005). In the case of natural aggregates with water absorption values of less than $1 \%$, the difference between $w / c$ and $w / c_{\text {eff }}$ is negligible. However, CRCA can have water absorption values up to $10 \%$ (Boehme et al., 2012) and therefore mixtures containing $1000 \mathrm{~kg}$ of CRCA in $1 \mathrm{~m}^{3}$ of concrete can easily contain 1001 of absorption water.

Besides their high water absorption values, a critical difficulty when working with CRCA is their heterogeneous nature. While natural aggregates generally come from the same resource, CRCA have several origins and qualities, leading to quality variation between different batches (Boehme et al., 2012; Padmini and Ramamurthy, 2009). The real water absorption of CRCA in 


\section{Offprint provided courtesy of www.icevirtuallibrary.com Author copy for personal use, not for distribution}

concrete plants is only periodically checked, with frequency depending on the standard used. Another problem CRCA concrete plants encounter is the variability of aggregate water content. While some plants have a continuous system in place to monitor this parameter, most plants rely on a daily sample. Any error in one of these two parameters leads to an over- or underestimation of the amount of compensation water.

In the study reported in this paper, five different types of concrete were created with deliberate errors in estimation of water absorption of CRCA in order to simulate the constraints at industrial plants.

\section{Research programme}

The geometric and physical properties of one batch of CRCA, resulting from housing demolition, were determined. These properties were aggregate size, grading, flakiness, density, water absorption, micro-deval and Los Angeles abrasion value. To measure the variability of water absorption, 50 different $1 \mathrm{~kg}$ samples were taken from this batch of CRCA. Taking into account the range of water absorption $( \pm 2 \sigma)$, five different concrete mixtures were made. Workability and density tests were conducted on the fresh concrete. After a $28 \mathrm{~d}$ curing period at $20^{\circ} \mathrm{C}$ and $90 \%$ relative humidity, water absorption (submersion and capillarity), dynamic modus of elasticity, compressive strength and tensile strength tests were conducted on the hardened concrete.

\section{Aggregate properties}

Two different aggregates were used in the experiment. Local washed sea sand 0/4 was used as fine aggregate and CRCA 8/20, originating from local housing demolition, was used as coarse aggregate. The combination of these two aggregates led to a gapgraded concrete design in which fraction $4 / 8$ was missing. The choice to remove the $4 / 8$ fraction was due to price on the one hand and, on the other, the fact that previous research has proven that CRCA $4 / 20$ properties are less favourable than those of CRCA 8/20 (Boehme et al., 2012). The different properties of the aggregates used are shown in Table 1.

\section{Mixture design}

The reference concrete mixture was designed to meet environmental class EE3 concrete requirements, which comprise frost and contact with rain (Anon, 2012). This implies a maximum w/c of 0.55 , a minimum cement dosage of $300 \mathrm{~kg} / \mathrm{m}^{3}$ and minimum compressive strength of $\mathrm{C} 25 / 30$. The concrete skeleton was designed by using the least-squares method and a Bolomey A16 equation (Belgische Betongroepering, 2009; Boehme et al., 2012)

$$
y=A+(100-A)(1 / D)^{1 / 2}
$$

where $y$ is the pass-through sieve $D \mathrm{~mm}(\%), d$ is the sieve width $(\mathrm{mm}), D$ is the maximum particle size $\left(D_{\max }\right)(\mathrm{mm})$ and $A$ is a constant.

Low-alkali cement (CEM III/A N LA 42.5) was used to reduce the risk of alkali-silica reaction. The total amount of water added in the mixing process was influenced by the water absorbed by the aggregates, which was added to the amount of water required for both hydration and workability. In the case of the reference concrete, the total amount of water was $220 \mathrm{~kg} / \mathrm{m}^{3}$ $\left(165+55 \mathrm{~kg} / \mathrm{m}^{3}\right)$. When less water is added to compensate for water absorption, an amount of free water is absorbed by the aggregates. This leads to a decrease in total concrete volume while the amount of cement added to the mixture remains constant. The resulting concrete will thus have a higher amount of cement dosage per cubic metre. Unfortunately, this effect, combined with a lower amount of free water, results in a lower effective w/c. The opposite is true when the water absorption of aggregates is overestimated. This leads to an increase in free water, resulting in a higher w/c. The five different mixes used in this work are detailed in Table 2.

Cubes $(150 \times 150 \times 150 \mathrm{~mm})$ and prisms $(100 \times 100 \times 500 \mathrm{~mm})$ were prepared for all the mixtures and both were used to determine the dry density of fresh and hardened concrete. The cubic specimens were also used to measure compressive strength and dynamic

\begin{tabular}{|c|c|c|c|c|c|c|c|}
\hline & \multicolumn{3}{|c|}{ CRCA } & \multicolumn{3}{|c|}{ Sea sand } & \multirow[t]{2}{*}{ Standard } \\
\hline & Value & $\sigma$ & Class & Value & $\sigma$ & Class & \\
\hline Aggregate size: $\mathrm{mm}$ & $8 / 20$ & - & - & $0 / 4$ & - & - & NBN EN 933-1:2012 \\
\hline Flakiness & $13 \cdot 3$ & $1 \cdot 3$ & Fl15 & - & - & - & NBN EN 933-3:2012 \\
\hline Shape & $11 \cdot 3$ & $1 \cdot 64$ & & - & - & - & NBN EN 933-4:2008 \\
\hline Micro-deval & $32 \cdot 3$ & $2 \cdot 6$ & MD35 & - & - & - & NBN EN 1097-1:2011 \\
\hline Los Angeles abrasion & $38 \cdot 7$ & $1 \cdot 4$ & LA40 & - & - & - & NBN EN 1097-2:2010 \\
\hline Absolute density, $\rho_{\mathrm{a}}: \mathrm{kg} / \mathrm{m}^{3}$ & 2694 & 153 & - & 2641 & 63 & - & NBN EN 1097-6:2006 \\
\hline Apparent dry density, $\rho_{\text {rd }}: \mathrm{kg} / \mathrm{m}^{3}$ & 2352 & 134 & - & 2589 & 62 & - & NBN EN 1097-6:2006 \\
\hline Saturated dry density, $\rho_{\text {ssd }}: \mathrm{kg} / \mathrm{m}^{3}$ & 2479 & 141 & - & 2608 & 62 & - & NBN EN 1097-6:2006 \\
\hline Water absorption: \% & $5 \cdot 4$ & $0 \cdot 77$ & - & 0.75 & $0 \cdot 1$ & & NBN EN 1097-6:2006 \\
\hline
\end{tabular}

Table 1. Geometrical and physical properties of aggregates 


\begin{tabular}{lccccc}
\hline & M1 & M2 & M3 & M4 & M5 \\
\hline Cement (CEM III/A N LA 42:5): $\mathrm{kg} / \mathrm{m}^{3}$ & 305 & 302 & 300 & 298 & 295 \\
Free water: $\mathrm{kg} / \mathrm{m}^{3}$ & 151 & 158 & 165 & 172 & 178 \\
Sea sand 0/4: kg/m & 794 & 787 & 781 & 775 & 769 \\
CRCA 8/20: $\mathrm{kg} / \mathrm{m}^{3}$ & 1050 & 1042 & 1033 & 1025 & 1017 \\
Used water absorption of CRCA: \% & 3.85 & 4.63 & 5.40 & $6 \cdot 17$ & 6.95 \\
Theoretical density of fresh concrete: $\mathrm{kg} / \mathrm{m}^{3}$ & 2355 & 2344 & 2334 & 2325 & 2314 \\
w/c ratio & 0.50 & 0.52 & 0.55 & 0.58 & 0.60
\end{tabular}

Table 2. Mix designs

modulus of elasticity, and prisms were used to test for flexural strength and splitting tensile strength.

\section{Mixing procedure}

Other research has demonstrated that the mixing process and duration can have a large impact on final recycled concrete quality (Tam et al., 2005). The mixing sequence, power and timings were held constant to minimise their influence on the properties of different batches and the mixer was wetted before starting the procedure. The aggregates and $50 \%$ of the total amount of water (absorption water and free water) were added to the mixer and mixed for $10 \mathrm{~min}$. The cement and the remaining water were then added and mixing continued for a further $10 \mathrm{~min}$. Once the second phase of the mixing process was complete, the mixture was allowed to settle for $5 \mathrm{~min}$. After mixing for a further $60 \mathrm{~s}$, the properties of the fresh concrete were determined.

\section{Experimental tests and results}

Workability

Workability is an important parameter to determine how recycled concrete is best handled at a construction site. Previous research has shown a large correlation between mixing time, the use of plasticiser and workability (Boehme et al., 2013). In this study, the mixing time was kept constant and no plasticisers were used. The consistency of the fresh concrete was measured using the Abrams slump test (EN 12350-2 (BSI, 2009a)) and the results are shown in

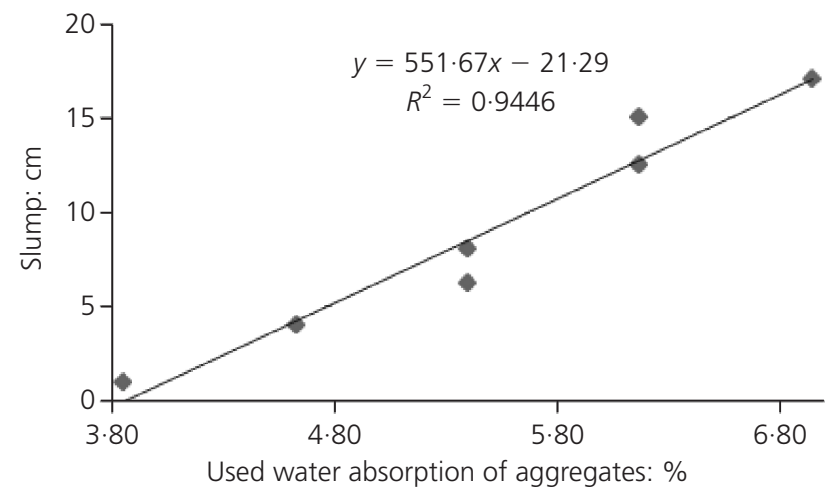

Figure 1. Influence of water absorption variability on workability
Figure 1. As shown in the figure, the relation between slump and amount of absorption water added followed a linear function, $y=551 \cdot 67 x-21 \cdot 29$, with $R^{2}=0 \cdot 94$. Every $1 \%$ difference between the used and the real water absorption of the recycled aggregates leads to a change of $\pm 5 \mathrm{~cm}$ in the measured slump.

Density

The method used for this test was according to EN 12350-6 (BSI, 2009b). The results are shown in Figure 2.

Due to the increased amount of free water in the mixture, the density of fresh and hardened concrete becomes significantly lower. The density of fresh concrete can be compared with the theoretical values given in Table 2 . The real values are a little higher $(+13 \mathrm{~kg} /$ $\mathrm{m}^{3}$ ) when using lower water absorption values, while the real density is $30 \mathrm{~kg} / \mathrm{m}^{3}$ below the theoretical value for higher water adsorption values. Comparing the fresh density curves with the theoretical data shows an intersection near $x=5 \cdot 4 \%$, the average water absorption of the aggregates used in mixture M3. This means that the density of fresh concrete can be used as an indicator to check the quality of the mixture when working with CRCA. The difference between hardened and fresh concrete is the result of

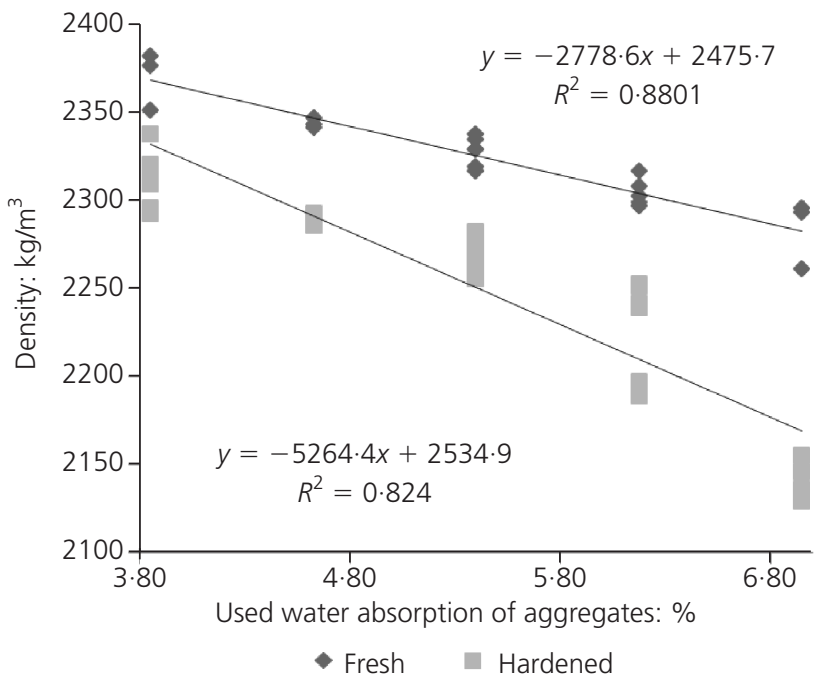

Figure 2. Influence of water absorption variability on density 
evaporation of free water and water inside the aggregates. The density of the hardened concrete samples in Figure 2, with the relation $y=-5264.4 x+2534.9\left(R^{2}=0.82\right)$, shows an increase in the difference between the density of fresh and hardened concrete when more absorption water is added. This will lead to an increase in porosity and permeability and probably result in decreased durability

\section{Compressive strength}

Much research has already been reported regarding the influence of porosity of aggregates and the equivalent water absorption on the compressive strength of recycled concrete. Li et al. (2006), Kou et al. (2007), Tang (2007) and Jin et al. (2008) concluded that compressive strength decreases as equivalent water absorption increases, with possible decreases in strength of up to 10 $25 \%$. An abundance of water in a concrete mix has the same negative effect on compressive strength. Models indicate that compressive strength is inversely proportional to the square of the amount of water in the mixture

$$
f_{\mathrm{c}, \mathrm{cub}}=K\left(\frac{1}{1+(w+a) / c}\right)^{2}
$$

where $f_{\mathrm{c} \text {,cub }}$ is the compressive strength $\left(\mathrm{N} / \mathrm{mm}^{2}\right), K$ is a cement constant, $c$ is the absolute volume of cement, $w$ is the total volume of water and $a$ is the total volume of air.

The formula $y=-244 \cdot 42 x+49 \cdot 38$, based on Figure 3, shows a linear decrease in compressive strength as a function of the amount of additional water added. Every 1\% misjudgement of real water absorption leads to a change of $2.5 \mathrm{MPa}$ or a difference of $7 \%$ in compressive strength.

\section{Splitting tensile strength}

Cheng (2005), Shi et al. (2010) and Zhou et al. (2010) investigated the influence of recycled concrete aggregates and $\mathrm{w} / \mathrm{c}$ ratio on the splitting strength of recycled concrete. They all

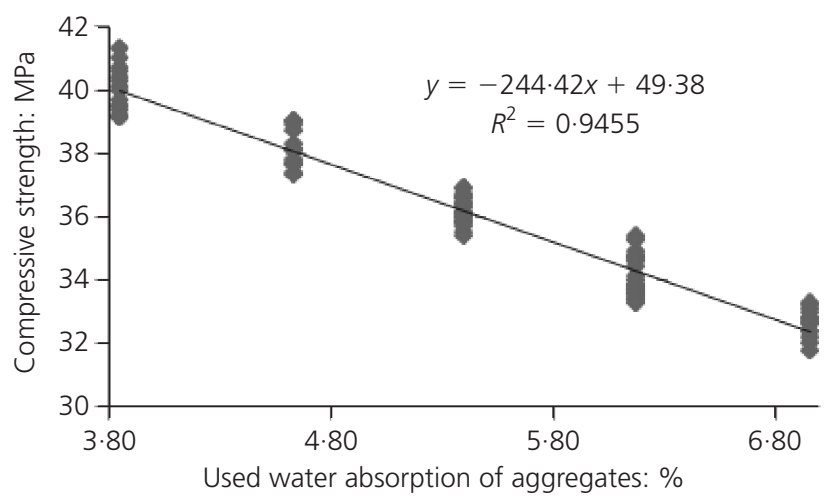

Figure 3. Influence of water absorption variability on compressive strength concluded that an increase in water absorption led to a significant drop in splitting tensile strength. Figure 4 shows a linear decrease in splitting strength as a function of the amount of additional water added $(y=-78 \cdot 73 x+6 \cdot 28)$. The total decrease between used water absorption values of $3.85 \%$ and $6.95 \%$ is $70 \%$, much more significant than the corresponding $20 \%$ loss in compressive strength.

\section{Flexural strength}

$\mathrm{Li}$ and Xiao (2005) and $\mathrm{Hu}$ (2007) concluded that replacement of natural aggregates by CRCA has only a slight impact (up to 10\%) on the flexural strength of recycled concrete. However, the equation produced from the results in Figure $5(y=-195 \cdot 03 x+16 \cdot 38)$ shows that an error in used water absorption leads to bigger differences. The difference in used water absorption values of $3 \cdot 85 \%$ and $6 \cdot 95 \%$ leads to a loss in flexural strength of up to $70 \%$.

\section{Modulus of elasticity}

Air present inside concrete decreases its dynamic modulus of elasticity because the velocity of sound through air is lower than the velocity through concrete. Since CRCA contain more air than natural aggregates, their use will decrease the dynamic modulus of elasticity of recycled concrete (Padmini and Ramamurthy,

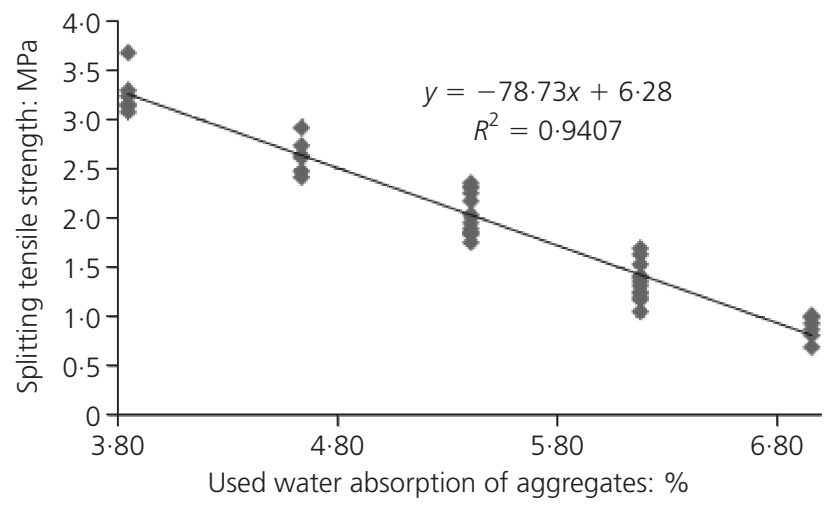

Figure 4. Influence of water absorption variability on splitting tensile strength

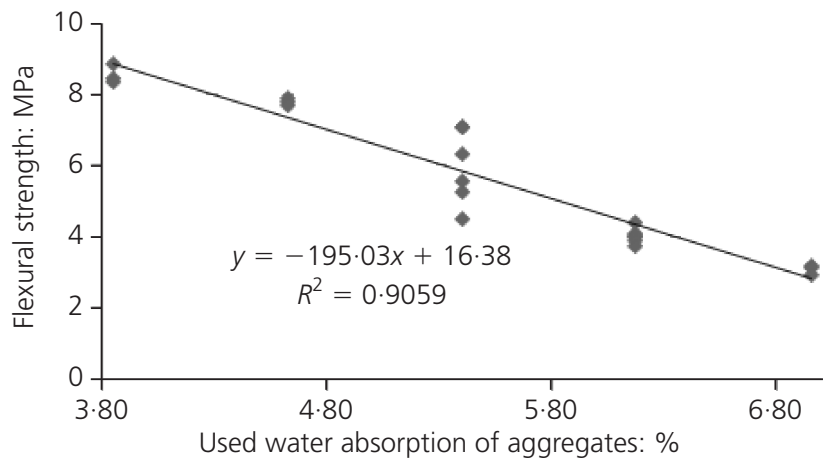

Figure 5. Influence of water absorption variability on flexural strength 
2009). Adding more water to a concrete mixture will lead to more pores after the evaporation process (Belgische Betongroepering, 2009). Overestimation of the water absorption of CRCA leads to a significant drop in modulus of elasticity.

As shown in Figure 6, every 1\% of additional water added leads to a drop of $5 \mathrm{GPa}$ in modulus of elasticity. This decrease is one of the reasons why the reduction in compressive strength is less significant than those in flexural and splitting strengths.

\section{Conclusions}

An overestimation of aggregate water absorption influences concrete quality in a similar way as an increase in w/c ratio - both lead to mechanical property loss and an increase in workability. These effects are not only due to an increase in free water, they are also amplified by a reduction in cement dosage. Water absorption underestimation effects are limited to workability loss, which can be compensated for by an increase in superplasticiser dosage. However, this increase, combined with a higher cement dosage, leads to more expensive concrete mixtures.

Fresh concrete density can be used as quick indicator to reveal errors in used water absorption values. Other quality tests used in standards are always based on mechanical properties measured after $28 \mathrm{~d}$ of hardening, which makes them unsuitable for use on construction sites.

Variability in CRCA water absorption is a problem for the industry. New industrial techniques such as mortar removal to reduce aggregate water absorption and prewetting systems to saturate aggregates without the need to determine the exact aggregate water absorption could be a solution. However, if those types of industrial processes are not used, the best way to cope with the situation is aggregate water absorption underestimation. While this leads to more expensive concrete, it is easier to remedy through the use of superplasticiser than having to deal with mechanically weak concrete.

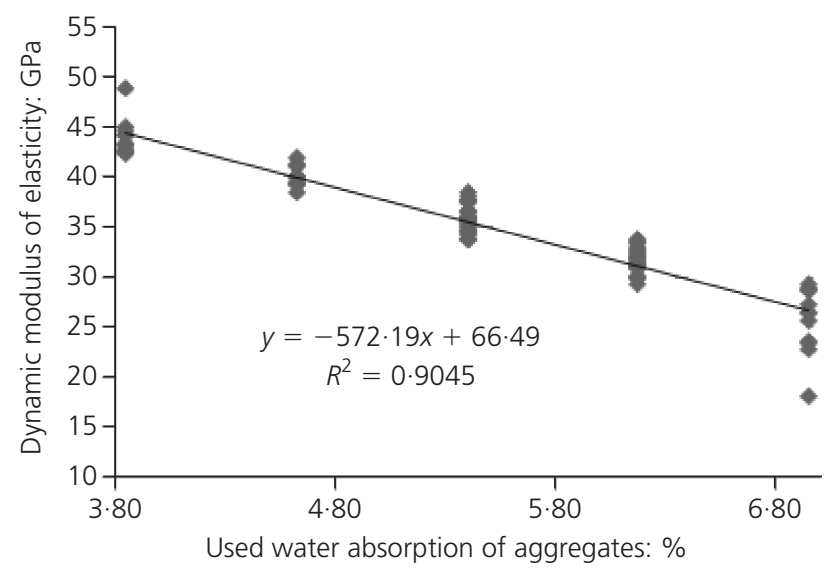

Figure 6. Influence of water absorption variability on dynamic elasticity modulus

\section{REFERENCES}

Anon (2012) NBN B 15-001: Beton - Specificatie, eigenschappen, vervaardiging en conformiteit - Nationale aanvulling bij NBN EN 206-1: 2001, sl: sn. Belgisch Instituut vor Nomalisatie, Brussels, Belgium (in Dutch).

Belgische Betongroepering (2009) Betonsamenstelling. De Bouwkroniek, Jette, Belgium, pp. 259-310 (in Dutch).

Boehme L, van Gysel A, Vrijders J, Joseph M and Claes J (2012) ValReCon20. KHBO, Ostend, Belgium.

Boehme L, Joseph M, Anseele T and Verstraete S (2013) Assessment of water reducing admixture in concrete with recycled aggregates. Proceedings of Central Europe towards Sustainable Building 2013, Prague, Czech Republic. Grada Publishing, Prague, Czech Republic, CESB13-1128, pp. 317$320)$.

BSI (2009a) EN 12350-2: 2009. Testing fresh concrete. Slump-test. BSI, London, UK.

BSI (2009b) EN 12350-6: 2009. Testing fresh concrete. Density. BSI, London, UK.

Cheng G (2005) Experimental study on the basic performance of recycled aggregate concrete with different displacement ratio. Chinese Concrete Journal 11: 67-70.

de Juan MS and Gutierrez PA (2009) Study on the influence of attached mortar content on the properties of recycled concrete aggregate. Construction and Building Materials 23(2): 872877.

Hu M (2007) Mechanical properties of concrete prepared with different recycled coarse aggregates replacement rate. Chinese Concrete Journal 2: 52-54.

Jin C, Wang X, Akinkurolere O and Jiang C (2008) Experimental research on the conversion relationships between the mechanical performance indexes of recycled concrete. Chinese Concrete Journal 11: 37.

Kou S, Poon C and Dixon C (2007) Influence of fly ash as cement replacement on the properties of recycled aggregate concrete. Journal of Materials in Civil Engineering 19(9): 709-717.

Li J and Xiao J (2005) Study on relationships between strength indexes of recycled concrete. Chinese Journal of Building Materials 9: 197-201.

Li J, Xiao J and Huang J (2006) Influence of recycled coarse aggregate replacement percentage on compressive strength of concrete. Chinese Journal of Building Materials 9(3): 297301.

Ovam (Openbare Vlaamse Afvalstoffenmaatschappij) (2014) Bedrijfsafvalstoffen productiejaar 2004-2012. OVAM, Mechelen, Belgium (in Dutch).

Padmini AK and Ramamurthy K (2009) Influence of parent concrete on the properties of recycled aggregate concrete. Construction and Building Materials 23(2): 829-836.

Pavlů T and Boehme L (2013) Properties and tests of recycled aggregates used in concrete. Proceedings of the YRSB13iiSBE Forum of Young Researchers in Sustainable Building 2013. Grada Publishing, Prague, Czech Republic, pp. 182 191. 
Shi X, Wang Q, Qiu C and Zhao X (2010) Experimental study on the properties of recycled aggregate concrete with different replacement ratios from earthquake-stricken area. Journal of Sichuan University 42(Supp. 1): 170-176.

Tam V, Gao X and Tam C (2005) Microstructural analysis of recycled aggregate concrete produced from two-stage mixing approach. Cement and Concrete Research. 35: 11951203.
Tang J (2007) Preliminary study on compressive strength of recycled aggregate concrete. Sichuan Building Science 33(4): 183-186.

WTCB (2005) Nieuwe normen voor beton (deel 2). Katern 6(6): 1-6 (in Dutch).

Zhou J, He H, Meng X and Yang Y (2010) Basic mechanical properties of recycled concrete. Experimental study. Journal of Shenyang Jianzhu University 11: 67-70.

\section{WHAT DO YOU THINK?}

To discuss this paper, please submit up to 500 words to the editor at journals@ice.org.uk. Your contribution will be forwarded to the author(s) for a reply and, if considered appropriate by the editorial panel, will be published as a discussion in a future issue of the journal. 